\title{
Combined pituitary hormone deficiencies, genetic forms
}

INSERM

\section{Source}

INSERM. (1999). Orphanet: an online rare disease and orphan drug data base. Combined pituitary hormone deficiencies, genetic forms. ORPHA:95494

Congenital hypopituitarism is characterized by multiple pituitary hormone deficiency, including somatotroph, thyrotroph, lactotroph, corticotroph or gonadotroph deficiencies, due to mutations of pituitary transcription factors involved in pituitary ontogenesis. Congenital hypopituitarism is rare compared with the high incidence of hypopituitarism induced by pituitary adenomas, transsphenoidal surgery or radiotherapy. 